\title{
TERAPI MUSIK TRADISIONAL UNTUK MENINGKATKAN KONSENTRASI, KEMANDIRIAN DAN HASIL BELAJAR SISWA ABK KELAS IV SDN INKLUSI SUMBERSARI I MALANG
}

\author{
Tri Istiningsih \\ Sekolah Dasar Negeri Tulusrejo 3 Kota Malang \\ e-mail:tri.istiningsih@yahoo.com
}

\begin{abstract}
This study are to describe the use and application of traditional music therapy in improving concentration, Independence, and Learning Outcomes in the fourth grade students ABK of SDN Sumbersari 1 Malang. This study used a qualitative approach. This research is Classroom Action Research (CAR). The subjects of this study were fourth grade students ABK at SDN Sumbersari 1 year 2012/2013 Malang. The results of this study indicate that traditional music therapy can improve concentration, independence and learning outcomes ABK fourth grade students at SDN Sumbersari 1 Malang. This is evidenced by the results of observations made during the month of January to May and the final results obtained by the percentage increase in the concentration rose between $33 \%$ to $47 \%$ and increased independence increased by $23 \%$ to $39 \%$. This resulted in an increase in the value of learning outcomes. Activities, especially playing traditional music gamelan and angklung, teaching and learning activities in the fourth grade students of SDN Inclusion unfortunate Sumbersari I looked more effective and fun.
\end{abstract}

\begin{abstract}
Abstrak: Penelitian ini bertujuan untuk mendeskripsikan penggunaan dan penerapan terapi music tradisional dalam meningkatkan Konsentrasi, Kemandirian, dan Hasil Belajar siswa ABK di kelas IV SDN Sumbersari 1 Malang. Penelitian ini menggunakan pendekatan kualitatif. Jenis penelitian ini adalah Penelitian Tindakan Kelas (PTK). Subyek penelitian ini adalah siswa ABK kelas IV SDN Sumbersari 1 tahun 2012/2013 Malang. Hasil penelitian ini menunjukkan bahwa terapi musik tradisional dapat meningkatkan konsentrasi, kemandirian dan hasil belajar siswa ABK kelas IV SDN Sumbersari 1 Malang. Hal ini terbukti dengan hasil pengamatan yang dilakukan selama bulan Januari sampai Mei dan hasil akhir yang diperoleh peningkatan prosentase konsentrasi naik antara 33\% sd $47 \%$ dan peningkatan kemandirian naik $23 \%$ sd 39\%. Hal ini berdampak pada peningkatan nilai hasil belajar. Kegiatan bermain musik tradisional khususnya gamelan dan angklung, kegiatan belajar mengajar pada siswa kelas IV SDN Inklusi Sumbersari I malang tampak semakin efektif dan menyenang.
\end{abstract}

Kata Kunci: Musik tradisional, konsentrasi,kemandirian, hasil belajar, siswa ABK

Kebijakan pemerintah dalam penuntasan Wajib Belajar Pendidikan Dasar SembiSembilan Tahun disemangati oleh seruan Internasional Education For All (EFA) yang dikumandangkan UNESCO sebagai kesepakatan global hasil World Education Forum di Dakar, Sinegal Tahun 2000, penuntasan EFA diharapkan tercapai pada Tahun 2015. Seruan ini senafas dengan semangat dan jiwa Pasal 31 UUD 1945 tentang hak setiap warga negara untuk memperoleh pendidikan dan Pasal 32 UU Sisdiknas Nomor 20 Tahun 2003 tentang Sistem Pendidikan Nasional yang mengatur mengenai pendidikan khusus dan pendidikan layanan khusus.

Pemerataan kesempatan belajar bagi anak berkebutuhan khusus dilandasi pernyataan Salamanca Tahun 1994. Pernyataaan Salamanca ini merupakan perluasan tujuan Education For All dengan mempertimbangkan pergeseran kebijakan mendasar 
yang diperlukan untuk menggalakkan pendekatan pendidikan inklusif. Melalui pendidikan inklusif ini diharapkan sekolah-sekolah reguler dapat melayani semua anak, termasuk mereka yang memiliki kebutuhan pendidikan khusus. Sehingga dapat mewujudkan pendidikan yang ber Bhineka Tunggal Ika. Di Indonesia melalui Keputusan Menteri Pendidikan dan Kebudayaan No.002/U/1986 telah dirintis pengembangan sekolah penyelenggaraan pendidikan inklusif yang melayani Penuntasan Wajib Belajar bagi peserta didik yang berkebutuhan khusus.

SD Sumbersari 1 adalah salah satu dari sekian banyak SD inklusi yang berada di Indonesi khususnya di kota Malang Jawa Timur yang berusaha memberikan layanan Inklusif untuk semua peserta didik tak terterkecuali siswa ABK. Sekolah Dasar Negeri yang berdiri sejak tahun 1968 ini merupakan sekolah dasar yang menjadi rintisan SD inklusi sejak tahun pelajaran 2005/2006 sampai sekarang. Pada tahun ajaran 2011/ 2012 SD inklusi Sumbersari 1 merupakan SD yang memiliki siswa ABK terbanyak se Indonesia, yaitu berjumlah 24 siswa.

Siswa-siswa ABK tersebut mempunyai karakter dan kebiasaan yang khusus (data terlampir), keberadaan mereka yang sedang tantrum dapat mengganggu teman sekelas yang mengakibatkan pembelajaran kurang dapat berjalan lancar, tidak jarang ketika situasi pembelajaran sedang berjalan kondusif mereka berteriak - teriak dan menangis tanpa sebab. Masalah yang lain adalah tidak semua siswa reguler dapat menerima keberadaan teman ABK dengan tangan terbuka. Keberadaan siswa ABK dirasa sangat mengganggu siswa reguler. Belum lagi kehadiran Shadow yang kadang kurang faham akan tugasnya juga menambah daftar terganggunya pembelajaran di kelas.

Jumlah siswa ABK yang terlalu banyak dan memiliki perbedaan jenis kekhususan yang berbeda juga sangat menyulitkan guru untuk mengkondisikan kelas. Sis- wa $\mathrm{ABK}$ yang terasesmen auties tentunya berbeda penanganannya dengan siswa yang terasesmen ADHD atau tunarungu. Permasalahan juga muncul pada diri siswa $\mathrm{ABK}$ itu sendiri, pada umumnya mereka merasa minder, kurang bersemangat, kurang aktif, kurang kreatif, tidak mandiri, kurang konsentrasi kadang asyik dengan dunia sendiri, acuh tak acuh pada sekitar,dan tidak dapat menstabilkan emosi. Kondisi yang kurang kondusif berdampak pada kurangnya pemahaman materi pada siswa reguler dan siswa $\mathrm{ABK}$ yang mengakibatkan tidak tercapainya hasil belajar yang memuaskan .

Pelaksanaan KBM dari hampir seluruh mata pelajaran belum bisa berjalan mulus dan dinyatakan berhasil, hal ini terlihat dari keaktifan siswa di kelas, sebagian besar siswa reguler sudah dapat mengikuti pembelajaran dengan lancar namun pada beberapa siswa $A B K$ masih belum konsentrasi, belum mandiri, kurang percaya diri dan masih menggantungkan diri pada Shadow. Walaupun pada siswa ABK tidak dituntut penguasaan materi setara dengan KKM namun diharapkan ada kemajuan dalam setiap kegiatan.

Kondisi tersebut guru harus dapat mengkondisikan pembelajaran yang efektif dan memilih strategi serta media pembelajaran yang tepat untuk konsentrasi, kemandirian dan peningkatan hasil belajar khususnya pada siswa ABK dan seluruh siswa pada umumnya. Upaya guru juga harus ditingkatkan agar siswa reguler dengan sadar dapat menerima teman-teman mereka ABK. ABK. Guru juga harus dapat menciptakan pembelajaran yang menyenangkan, tidak menjenuhkan dan berkesan untuk peserta didik. Salah satunya dengan memperhatikan pengaturan jadwal pelajaran tiap hari. Ada 8 jam pelajaran dalam satu hari untuk hari Senin sampai kamis dan 6 jam pelajaran untuk Jum'at dan Sabtu. Pelajaran yang sifatnya eksak yang membutuhkan konsentrasi penuh seperti matematika dapat dijadwalkan dengan pelajaran yang lebih rileks se- 
perti Seni Budaya \& Ketrampilan dalam hari yang. Hal ini diupayakan agar otak sebelah kanan dan kiri berjalan seimbang.

Berdasarkan uraian permasalahan diatas, maka peneliti melakukan Penelitian Diskriptif berbertuk Penelitian Tindakan Kelas dengan judul "Terapi Musik Tradisional untuk Meningkatkan Konsentrasi, Kemandirian dan Hasil Belajar Belajar Siswa ABK Kelas IV SDN Inklusi Sumbersari Malang"

\section{METODE PENELITIAN}

Pendekatan penelitian yang digunakan dalam penelitian ini adalah pedekatan kualitatif yang bersifat alami apa adanya, dan tidak ada manipulasi data. Menurut Moleong, (dalam Khoiriyah, 2010: 33) "Peneliti kualitatif berusaha berinteraksi dengan subyek penelitinya secara alamiah. Penelitian dimaksudkan untuk mendeskripsikan peristiwa-peristiwa sebagaimana yang terjadi secara alami melalui pengumpulan data yang kemudian data tersebut dipaparkan dalam bentuk kalimat (deskriptif)".

Jenis penelitian yang digunakan adalah Penelitian Tindakan Kelas (PTK). "PTK adalah proses investigasi terkendali untuk menemukan dan memecahkan masalah pem belajaran di kelas, proses pemecahan masalah tersebut dilakukan secara bersiklus, dengan tujuan untuk meningkatkan kualitas pembelajaran dan hasil pembelajaran di kelas tertentu" (Akbar, 2010:26). Model PTK yang dilakukan dalam penelitian ini adalah Penelitian Tindakan Kelas Kolaboratif ( $\mathrm{Co}$ llaborative Classroom Action Research). Pe neliti selaku pelaku tindakan dan Guru Pem bimbing Khusus (GPK) sebagai observer.

Meskipun penelitian direncanakan secara bersiklus, tetapi peneliti tidak bisa menentukan di awal, berapa siklus penelitian ini akan berakhir. Penelitian akan diakhiri jika sudah terjadi peningkatan kualitas proses dan hasil pembelajaran. Meskipun penelitian ini tidak ditentukan banyaknya siklus, namun penelitian ini akan merencanakan aktivitas pada siklus I yang tahapannya terdiri atas perencanaan, tindakan, observasi, dan refleksi.

Pengumpulan data dilakukan dengan teknik Observasi, assesment, wawancara, dokumentasi, pengamatan dan tes. Assesment dilakukan untuk mengetahui jenis ketunaan pada siswa ABK dan kebiasaan tantrum yang dilakukan, wawancara dilakukan pada wali siswa, shadow dan GPK. Selanjutnya dilakukan observasi dan pengama$\tan$.

Wawancara dilakukan kepada guru yang pernah mengajar rombongan belajar siswa kelas IV tahun 2011/2012, yaitu guru kelas I, II dan III, wali kelas siswa ABK, Shadow yang mendampingi siswa serta Guru Pembimbing Khusus. Hal ini dilakukan agar peneliti mendapatkan data yang lengkap serta dapat menentukan langkah yang tepat dalam melaksanakan pembelajaran dan pembimbingan pada siswa kelas IV pada umumnya dan siswa ABK pada Khususnya.

Dokumentasi dilakukan untuk mengumpulkan data tentang berbagai peristiwa dalam proses pembelajaran melalui foto, dokumen yang berupa karya siswa, dokumen portofolio, dan hasil pembelajaran. Pengamatan dilakukan khususnya pada siswa ABK, hal ini dikhususkan pada perkembangan konsentrasi dan kemandirian. Pengamatan ini dilakukan tiap hari yang dilaksanakan oleh Guru Pembimbing Khusus selaku observer.

Analisis data dilakukan secara deskriptif, baik deskriptif kualitatif maupun kuantitatif. Analisis data secara kualitatif mengikuti prosedur analisis data secara kualitatif. Pada umumnya analisis data secara kualitatif dilakukan dengan tahap-tahap: pemaparan data, reduksi data, kategorisasi data, penafsiran/pemaknaan, dan penyimpulan hasil analisis.

Pemaparan data merupakan upaya menampilkan data secara jelas dan mudah dipahami dalam bentuk naratif, grafik, atau 
bentuk lainnya. Reduksi data merupakan proses penyederhanaan data yang dilakukan melalui proses seleksi, pengelompokkan, dan pengorganisasian data mentah menjadi sebuah informasi yang bermakna. Penyimpulan merupakan upaya pengambilan intisari dari sajian data yang telah terorganisasi dalam bentuk pernyataan atau kalimat yang singkat, padat, dan bermakna.

Analisis data yang bersifat deskriptif kuantitatif dilakukan dengan analisis prosentase perkembangan konsentrasi dan kemandirian siswa serta hasil belajar siswa ABK.

Untuk menganalisis tingkat keberhasilan atau persentase keberhasilan siswa setelah proses belajar mengajar setiap putarannya dilakukan dengan cara menghitung hasil pengamatan pada setiap akhir putaran yaitu tiap bulan atau setiap 4 minggu.

Untuk menghitung persentase ketuntasan belajar digunakan rumus sebagai berikut:

$$
P=\frac{\sum \text { Siswayang.tuntas.belajar }}{\sum \text { Siswa }} \times 100 \%
$$

\section{HASIL DAN PEMBAHASAN}

Pada kegiatan ini dilaksanakan penngamatan dan observasi tingkah laku siswa didalam dan diluar kelas serta mempelajari hasil assesmen dari Psikiater. Mengamati kebiasaan dan kendala yang muncul, mempelajari data hasil assesment dari lembaga assesment, mengenal jenis ketunaan siswa ABK serta melakukan wawancara dengan wali siswa, Shadow dan Guru yang pernah mengajar siswa ABK tersebut dari kelas 1,2 dan 3. Hal ini dilakukan untuk mengetahui keberadaan dan kemajuan siswa ABK yang ada yang sekarang duduk di kelas IV.

Dari data hasil observasi selanjutnya akan dijadikan dasar dalam melaksanakan langkah penelitian. Adapun deskripsi data kondisi awal dapat dipaparkan di bawah ini. Ada 5 siswa ABK di kelas IV SDN Inklusi
Sumbersari I Malang, untuk menjaga prevasi mereka kami memfiktifkan namanyan menjadi Adam, Beni, Carli, Dani dan Elan.

Berdasarkan observasi yang dilakukan peneliti diperoleh data hasil belajar siswa pada proses kegiatan pra tindakan masih kurang memuaskan, siswa ABK masih kurang aktif, kreatif dan mandiri dalam penyelesaian tugas. Masih 4 dari 5 anak ABK yang bergantung pada Shadow. Dengan prosentase $4 / 5 \times 100 \%=80 \%$ sehingga keberhasilan siswa ABK masih $20 \%$.

\begin{tabular}{|c|c|c|c|c|}
\hline \multicolumn{5}{|c|}{ siswa ABK Kopdisi awal } \\
\hline No & Sama & Konsentras & Kemandirian & Hasil Relajar \\
\hline 1 & Adam & $20 \%$ & $20 \%$ & $46 \%$ \\
\hline 2 & Beni & $40 \%$ & $60 \%$ & $46 \%$ \\
\hline 3 & Cerli & $40 \%$ & $40 \%$ & $43 \%$ \\
\hline 4 & Dani & $60 \%$ & $40 \%$ & $45 \%$ \\
\hline 5 & Elan & $60 \%$ & $60 \%$ & $60 \%$ \\
\hline \multicolumn{2}{|c|}{ Rata - rata } & $44 \%$ & $44 \%$ & $48 \%$ \\
\hline
\end{tabular}

Hasil Pengamatan Konsentrasi

\begin{tabular}{|l|l|c|c|c|c|c|c|}
\hline No & Nama & Januari & Pebruari & Maret & April & Mei & Prosentase \\
\hline 1 & Adam & 52 & 42 & 41 & 38 & 35 & $17552 \times 100 \%=33 \%$ \\
\hline 3 & Beni & 51 & 41 & 38 & 39 & 32 & $19 / 51 \times 100 \%-37 \%$ \\
& Carll & 52 & 40 & 38 & 34 & 32 & $20 ; 52 \times 100 \%=38 \%$ \\
\hline 4 & Dani & 36 & 36 & 35 & 32 & 29 & $17 / 36 \times 100 \%-47 \%$ \\
\hline 5 & Flan & 36 & 34 & 35 & 33 & 29 & $17 / 36 \times 10 n \%=47 \%$ \\
\hline
\end{tabular}

\begin{tabular}{|c|c|c|c|c|c|c|c|}
\hline \multicolumn{8}{|c|}{ Hasil Pengamatan Kemandirlan } \\
\hline No & Nama & Januari & Pebruari & Maret & April & Mei & Prosentase \\
\hline 1 & Adam & 52 & 17 & 15 & 44 & 10 & $12 / 52 \times 100 \%=23 \%$ \\
\hline 2 & Reni & 49 & 44 & 40 & 35 & 30 & 19/49x100\% $-39 \%$ \\
\hline 3 & Carti & 46 & 42 & 40 & 37 & 31 & $15 / 46 x 100 \%-32 \%$ \\
\hline 1 & Dani & 19 & 17 & 12 & 40 & 35 & $1 / 1 / 19 \times 100 \%=29 \%$ \\
\hline 5 & Elan & 42 & 42 & 40 & 38 & 32 & $10 / 42 \times 100-24 \%$ \\
\hline
\end{tabular}

Pada setiap pertemuan mulai terlihat perubahan pada siswa,terutama pada siswa ABK. Siswa yang terassesment auties mulai tampak memiliki rasa percaya diri dan terlihat mulai mandiri, siswa tuna rungu mulai dapat menanggalkan alat bantu dengarnya dan mengobtimalkan pendengarannya. 
Dari kegiatan yang dilaksanakan selama satu semester dengan bermain alat musik tradisional terlihat seluruh siswa lebih bergembira, bersemangat, saling menyayangi dan saling akrab. Dalam proses pembelajaran siswa terlihat saling menghargai, mereka tidak segan lagi berbaur dalam satu kelompok antara siswa reguler dan siswa ABK dalam menyelesaikan tugas kelompok. Siswa ABK mulai bersemangat, lebih aktif, lebih bisa berkonsentrasi, terlihat mandiri (tidak tergantung Shadow) dan hasil belajar mereka mengalami peningkatan.

\section{KESIMPULAN}

Dari hasil penelitian tampak perkembangan Konsentrasi dan Kemandirian Siswa ABK dari hari ke hari semakin meningkat. Hal ini terbukti dengan hasil pengamatan yang dilakukan selama bulan Januari sampai Mei dan hasil akhir yang diperoleh peningkatan prosentase konsentrasi naik antara $33 \%$ sd $47 \%$ dan peningkatan kemandirian naik $23 \%$ sd $39 \%$. Hal ini berdampak pada peningkatan nilai hasil belajar

Kegiatan dan situasi pembelajaran yang kondosif merupakan kunci keberhasilan dalam proses belajar mengajar demi terwujudnya cita-cita Pendidikan Nasional. Guru harus piawai dalam mengkondisikan kelas mulai dari memilih materi, menetapkan strategi dan metode pembelajaran yang efektif dan efisien, memilih media yang tepat dan dapat memanfaatkan sumber belajr yang ada dilingkungan sekitar serta komponen lain yang mendukung pembelajaran.

Terapi bermain musik tradisional adalah salah satu strategi dan media yang tepat untuk meningkatkan konsentrasi, kemandirian serta hasil belajar terutama pada siswa ABK. Selain itu ada dampak positif yang lain seperti saling menghargai, saling menyayangi, melatih kerja sama, dan menumbuhkan rasa cinta terhadap budaya sebagai akar cinta Negara Kesatuan Pepublik Indonesia.
Setelah dilakukan kegiatan bermain musik tradisional khususnya gamelan dan angklung, kegiatan belajar mengajar pada siswa kelas IV SDN Inklusi Sumbersari I malang tampak semakin efektif dan menyenangkan. Khususnya siswa ABK mulai memiliki konsentrasi, kemandirian yang akhirnya meningkatkan hasil belajarnya.

\section{DAFTAR PUSTAKA}

Abimanyu, Soli, dkk. 2009. Strategi Pembelajaran. Jakarta. Departemen Pendididikan Nasional.

Akbar, Sa dun. 2010. Prosedur Penyusunan Laporan dan Artikel PTK, Yogyakarta. Cipta Media.

Alimin, Z. 2010. Makalah Seminar Nasional: Reorientasi Pendidikan Khusus/ PLB ke pendidikan Kebutuhan Khusus Sebagai Usaha Mencapai Pendidikan Untuk Semua. Malang: UM.

Arsyad, Azhar. 2009. Media Pembelajaran, Jakarta, PT Raja Grafindo Persada

Anonim. 2003. Penilaian Berbasis Kelas Materi Pelatihan PKG SJ SBK.

Busi, Putu. 2003. Bio Authentic Assesment. Klipping. Gramedia Jakarta

Depdiknas. 2004. Mengelola Kelas Inklusi Dengan Pembelajaran Yang Ramah. Jakarta: Direktorat PSLB.

Depdiknas. 2007. Manajemen Pendidikan Inklusi. Jakarta: Depdiknas.

Siddiq M Djauhar, Isniatun Munawaroh. 2009. Pengembangan Bahan Pembelajaran SD. Jakarta. Departemen Pendidikan Nasional.

Anonim. 2003. Penilaian Berbasis Kelas Materi Pelatihan PKG SJ Seni Budaya dan Ketrampilan.

Busi, Putu. 2003. Bio Authentic Assesment. Klipping. Gramedia Jakarta.

Akbar, Sadun. 2010 Prosedur Penyusunan. Laporan dan Artikel PTK. Yogyakarta. Cipta Media. 